TJVR 2021; 5 (2): 89-97

Turkish Journal of Veterinary Research

https://dergipark.org.tr/tr/pub/tjvr

e-ISSN: 2602-3695

\title{
Investigation of the nutritional and quality properties of meatballs added with bee pollen and apigenin
}

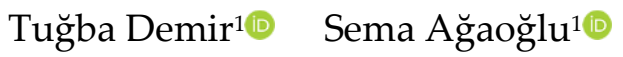 \\ ${ }^{1}$ Department of Food Hygiene and Technology, Faculty of Veterinary Medicine, Sivas Cumhuriyet University, Sivas, Turkey
}

\begin{abstract}
Objective: The present study was carried out to investigate the possibility of using different levels of bee pollen and apigenin extract in beef meatballs to evaluate shelf-life, nutritional and quality properties of beef meatballs under different storage conditions.

Materials and Methods: It was determined, using the HPLC method, that bee pollen contains a high level of apigenin under optimal conditions. Bee pollen and apigenin were added to meatballs at different concentrations in five groups. Meatballs were made with control, 1-2\% bee pollens/apigenin. Quality and safety evaluation of meatballs were determined by sensory, physicochemical, biochemical and microbiological tests. The analyses were conducted at 1st, 3rd, 7th and 14th days of interval.
\end{abstract}

Results: A statistically significant decrease was found in FFA, POV and TBARS levels of meatballs on different days of storage $(\mathrm{p}<0.05)$. When compared to the control group, the bioactive compounds preserved the microbiological and chemical properties of meatballs during frozen storage (14 days).

Conclusion: It was concluded that the extracts with $2 \%$ bee pollen concentrations can be used as biopreservative agents for meat and meat products.

Keywords: Bee pollen, Apigenin, Meatballs, Food quality

\section{INTRODUCTION}

Natural compounds such as omega-3 fatty acids, vitamin $\mathrm{E}$, conjugated linolenic acid (CLA), selenium (Se), herbs, spices, pre- and probiotics, phytochemicals and bioactive peptides are among the technologies used in developing qualified meat products (Zhang et al., 2010; Manessis et al., 2020). Meat and meat products are effective substrates for the development and growth of common foodborne pathogens. Thus, these foods are highly risky and easily spoiled, causing possible public health issues (Chen et al., 2012; Doulgeraki et al., 2012). Food spoilage is a process that causes foods to be undesirable or unacceptable for consumers for changes in sensory characteristics (Burkepile et al., 2006). Oxidative changes (lipid and protein oxidation) occur faster in meat. It was reported that it might be because the meat surface area in contact with air significantly increases after mincing the meat (Turgut et al., 2016).

Oxidative reactions are among the major interactions of meat spoilage after the butchering process. The high levels of myoglobin and ferrous content of beef meat, which is in the class "red meat", are one of the reasons for strong peroxide formation (Jiao et al., 2020). Increasing the functional and nutritional value of foods and prolonging the storage period by adding phenolic compounds into meats and meat products are among the focus points of studies carried out on this subject (Hintz et al., 2015). Natural additives containing phenolic compounds are added directly 
into meats and meat products in order to improve the antimicrobial and antioxidant properties of the product, as well as the quality characteristics during the storage period (Ahn et al., 2004).

Bee pollen is a fine powder-like material produced by flowering plants pollen, mixed with nectar and bee secretions and collected by honey-bees (Graikou et al., 2011). Bee pollen is an apicultural product and it has been recommended in nutrition, for its nutritional contents and health benefits (Freire et al., 2012). It is known that bee pollen contains lipids, sugars, proteins, amino acids, vitamins, mineral substances, trace elements, carotenoids, polyphenolics such as flavonoids, and carbohydrates with these features, bee pollen is a source of biologically active substances (Human and Nicolson, 2006).

Bioactive phytochemicals compounds are contemplated beneficial for immune system support since they decrease the risk of inflammation by reducing oxidative stress and inhibiting free radicals. (Demir and Ağaoğlu, 2020; Demir, 2021). They have been shown to possess free-scavenging and metal chelating activity in addition to their reported antimicrobial and antioxidant properties (Morais et al., 2011). The high antioxidant potential of bee pollen is associated with the presence of flavonoids and polyphenols in its content (Rzepecka-Stojko et al., 2012). The present study was carried out to investigate the possibility of using different levels of bee pollen and apigenin extract in beef meatballs to evaluate shelf-life, nutritional and quality properties of beef meatballs under different storage conditions.

\section{MATERIALS and METHODS}

Preparation of bee pollen extracts, standard phytochemical (Apigenin) and meatball groups

Bee pollen were obtained from producer (Turkey). Extraction solution was prepared before grouping. The extract was concentrated to dryness under low pressure and controlled temperature. For the extraction of phenolic compounds in bee pollen, samples were mixed with methanol at $1: 10(\mathrm{~g}: \mathrm{mL})$ ratio and vortexed for 10s. The methanolic phase was separated by centrifugation at $6000 \mathrm{rpm} \times 3 \mathrm{~g}$ at room temperature for $10 \mathrm{~min}$. High Performance Liquid Chromatography (HPLC) grade apigenin was used compared against the natural extracts. In the preparation of standard solutions, the purchased firm was made by examining the SDS package insert to Sigma-Aldrich (St. Louis, MO, ABD). The control (C) and four treatment groups were determined for meatballs. These groups were $1 \%$ bee pollen (P1), $2 \%$ bee pollen (P2), $1 \%$ Apigenin (A1), $2 \%$ Apigenin (A2), respectively.

\section{Preparation of meatballs}

Ground beef was purchased from a local butcher in Sivas, Turkey. Beef minced meat and salt were used in preparing the samples. The meat is mixed and 20 $\mathrm{g}$ of salt per kilo is added, and it is minced once in a medium thickness in the meat grinder. Bee pollen or Apigenin were added to the formulation of meatballs. The remaining group without any addition was used as a control. Kneading was performed after each component was added to the meatball mortar at the rate of $1 \%$ and $2 \%$, respectively. In order for the meatballs to be of standard size and shape, samples were prepared as one meatball weighing $25 \mathrm{~g}$, with the help of a shaping machine. All the experiments were performed three times (three different groups).

\section{Biochemical analysis and microbial assessment}

Free fatty acid values (FFA): Samples (5 g) were dissolved with $30 \mathrm{~mL}$ of chloroform using a homogenizer (IKA Ultra-Turrax T18 Basic, Staufen, Germany) (10,000 rpm; $1 \mathrm{~min})$. Whatman No. 1 was used to remove the filtrate. The resulting filtrate (added phenolphthalein) was titrated $(0.01 \mathrm{~N}$ $\mathrm{KOH})$. The FFA value was calculated with the formula (Rukunudin et al., 1998).

Peroxide value (POV): The POVs of meatball samples were determined according to the method by Volpe et al. (2015) and Shahbazi et al. (2018). The samples $(3 \mathrm{~g})$ were weighed and heated in a water bath at $60{ }^{\circ} \mathrm{C}$ for $3 \mathrm{~min}$ (to melt the oil). The flasks were then shaken for $3 \mathrm{~min}$ with acetic acidchloroform solution (3:2 by volume). Whatman No. 1 was used to re-move the filter. Saturated potassium iodide solution $(0.5 \mathrm{~mL})$ was added to the final filtrate (indicator starch). The titration process was continued against the standard sodium thiosulfate solution. The POV was determined in the total lipid extracts and calculated with the formula. Results are given as POV (meq $/ \mathrm{kg})$.

Thiobarbituric acid reactive substances (TBARS): Lipid oxidation was measured with 2-thiobarbituric acid reagent, as modified by Sharma et al. (2012). Values (1,1,3,3-tetraethoxypropane) were calculated by drawing the standard curve $(y=a x+$ b) and expressed as milligram of malondialdehyde per kilo-gram of meatball sample (mg MA/kg). 
Total Viable Count (TVC), Total Coliform Count (TCC) and Total Yeast Mold Count (TYMC) were determined according to TS EN ISO 4833-1, TS ISO 4832, TS ISO 21527-1 (TSE, 2010; TSE, 2012; TSE, 2014;). All analyses were done in triplicate and mean value was reported.

\section{Analysis of phenolics}

Phenolic compounds were separated using HPLC (Agilent 1200), analysis (Mohdaly et al., 2015) were performed by modifying the HPLC method. The column used ZORBAX SB-C18 (4.6mm x 250mm x $5 \mu \mathrm{m})$, (Agilent Technoliges, USA). Different phenolic components were separated using a gradient of water containing 30\% methanol (Solvent A) and methanol $100 \%$ (Solvent B), at a flow rate of $40 \mu \mathrm{L} / \mathrm{min}$ in following gradient elution: $25-100 \%$ Solvent B over $40 \mathrm{~min}, 50 \%$ Solvent B for $10 \mathrm{~min}$, followed by $10 \mathrm{~min}$ for coloum calibration. The column temperature was maintained at $25^{\circ} \mathrm{C}$ and the phenolic compound was carried recorded at 280 $\mathrm{nm}$. Solutions of pure eleven phenolic compounds were chromatographed as external standards. All standards were dissolved in methanol before injection in the analytical HPLC system.

\section{Sensory evaluation}

Different sensory attributes were examined. The meatball samples were assessed by a trained 8member panel. The sensory questionnaires were calculated intensity on a 5-point balanced semantic scale for the attributes of color, smell, tenderness, juiciness, and overall acceptability. The evaluation method was based on the method used by Rubito et al. (2007). Sensory evaluation was had accomplished at 0 day and repeated at 1, 3, 7 and 14 days.

\section{RESULTS}

Results of the microbiological analyses of the meatballs formulated with different levels of bee pollen/apigenin during the 14 days storage (period) time are showed in Table 1 . The results of all microbiological analyses were influenced by both bee pollen added (except 0 days of storage) and storage period $(p<0.05)$. The range of TVC value, TCC value and TYMC values at different days of interval was 4.60 to $4.61,0.98$ to 1.13 and 1.22 to 1.71 $\operatorname{logs} \mathrm{cfu} / \mathrm{g}$, respectively. In all storage periods the highest TVC was observed in control samples $(\mathrm{p}<0.05)$, and in general, TVC decreased as the pollen content/apigenin content increased ( $\mathrm{P} 2<\mathrm{P} 1$, $\mathrm{A} 2<\mathrm{A} 1$ ) (Table 1). Among these five treatments, the TCC in control sample (1.11 logs cfu/g) was significantly higher than in the samples treated with $\mathrm{P} 1, \mathrm{P} 2, \mathrm{~A} 1$, and $\mathrm{A} 2$ of bee pollen/apigenin extracts. Similar to TVC, in all storage periods (except 0 days of storage), the highest TCC count was control samples and at the end of the storage period, TCC count decreased to minimum levels of 1.11 (C), 1.10 (P1), 1.04 (P2), 1.03 (A1) and 1.01 logs cfu/g (A2) for control and meatballs added with $1 \%, 2 \%$ bee pollen and $1 \%, 2 \%$ apigenin, respectively (Table 1 ).

Sensory scores for parameters such as color, flavor, tenderness, juiciness and overall acceptability were significantly affected $(\mathrm{p}<0.05)$ by the addition of bee pollen and apigenin (Table 2). The analysis of phenolic compounds is very challenging due to the great variety and reactivity of these compounds. For the purpose of separation and quantification of individual phenolic compounds, HPLC is most frequently used because of its high separation capacity and relative simplicity. To know that are responsible active ingredients in bee pollen extract, methanol extracts were used for further investigations toward identification by HPLC. The biochemical effects of bee pollen/apigenin on meatball samples are shown in Figures 1-3. The overall FFA, POV and TBARS value at different treatment was $0.37-0.46 \%, 4.23-4.54 \mathrm{meq} / \mathrm{kg}$ and 0.52-0.66 mgMA $/ \mathrm{kg}$, respectively.

\section{DISCUSSION}

Considering the data obtained from this study, it was observed that there were significant differences in TYMC values between the five experimental groups. Among five treatments, TYMC in the control sample (1.68 logs cfu/g) were significantly higher than in the samples treated with bee pollen (P1, P2) and apigenin (A1, A2) extracts. Many bacteria might be available in the products, however these microorganisms growing may be controlled under storage conditions (Fernandeslopez et al., 2005).

These results show that bee pollen and apigenin inhibited the bacterial growth (Graikou et al., 2011). The antimicrobial activity of bee pollen could be property chiefly to the effective contents of flavonoids and phenolic compounds such as apigenin, gallic acid, quercetin and kaempferol whichever are identified to possess antimicrobial and antifungal activity (Mohdaly et al., 2015). In present study was explored that sensory quality after added bee pollen/apigenin extracts was changed with the storage process. 
Table 1. Effect of bee pollen and apigenin extracts on microbial population in beef meatballs (log cfu/g).

\begin{tabular}{|c|c|c|c|c|c|c|c|c|c|c|c|c|}
\hline $\begin{array}{c}\text { Microbiological } \\
\text { analysis }\end{array}$ & $\begin{array}{c}\text { Storage } \\
\text { Period }\end{array}$ & $\mathrm{C}$ & SD & P1 & SD & P2 & SD & A1 & SD & A2 & SD & Mean* \\
\hline \multirow{5}{*}{$\begin{array}{c}\text { TCC } \\
\text { (Total Coliform } \\
\text { Count) }\end{array}$} & 1 & 1.18 & 0.03 & 1.13 & 0.02 & 1.11 & 0.02 & 1.12 & 0.03 & 1.10 & 0.01 & 1.13 \\
\hline & 3 & 1.13 & 0.02 & 1.11 & 0.01 & 1.07 & 0.02 & 1.06 & 0.03 & 1.06 & 0.04 & 1.09 \\
\hline & 7 & 1.10 & 0.02 & 1.10 & 0.02 & 1.03 & 0.03 & 1.01 & 0.03 & 0.96 & 0.04 & 1.04 \\
\hline & 14 & 1.03 & 0.02 & 1.06 & 0.02 & 0.96 & 0.03 & 0.94 & 0.07 & 0.91 & 0.07 & 0.98 \\
\hline & Mean* & 1.11 & 0.01 & 1.10 & 0.01 & 1.04 & 0.01 & 1.03 & 0.03 & 1.01 & 0.03 & \\
\hline \multirow{5}{*}{$\begin{array}{c}\text { TVC } \\
\text { (Total Viable } \\
\text { Count) }\end{array}$} & 1 & 4.86 & 0.02 & 4.63 & 0.02 & 4.53 & 0.03 & 4.61 & 0.03 & 4.42 & 0.02 & 4.61 \\
\hline & 3 & 4.88 & 0.04 & 4.65 & 0.04 & 4.60 & 0.02 & 4.59 & 0.04 & 4.53 & 0.02 & 4.65 \\
\hline & 7 & 4.99 & 0.07 & 4.67 & 0.01 & 4.62 & 0.01 & 4.60 & 0.03 & 4.46 & 0.04 & 4.67 \\
\hline & 14 & 5.09 & 0.02 & 4.52 & 0.02 & 4.53 & 0.02 & 4.50 & 0.01 & 4.34 & 0.04 & 4.60 \\
\hline & Mean* & 4.95 & 0.03 & 4.62 & 0.01 & 4.57 & 0.00 & 4.57 & 0.02 & 4.44 & 0.02 & \\
\hline \multirow{5}{*}{$\begin{array}{c}\text { TYMC } \\
\text { (Total Yeast Mould } \\
\text { Count) }\end{array}$} & 1 & 1.82 & 0.02 & 1.68 & 0.04 & 1.69 & 0.05 & 1.62 & 0.05 & 1.71 & 0.03 & 1.71 \\
\hline & 3 & 1.77 & 0.02 & 1.50 & 0.03 & 1.46 & 0.02 & 1.42 & 0.02 & 1.36 & 0.04 & 1.50 \\
\hline & 7 & 1.62 & 0.05 & 1.34 & 0.03 & 1.27 & 0.04 & 1.28 & 0.03 & 1.18 & 0.02 & 1.34 \\
\hline & 14 & 1.51 & 0.09 & 1.25 & 0.02 & 1.16 & 0.03 & 1.12 & 0.02 & 1.06 & 0.03 & 1.22 \\
\hline & Mean* & 1.68 & 0.01 & 1.44 & 0.02 & 1.40 & 0.02 & 1.36 & 0.02 & 1.33 & 0.02 & \\
\hline
\end{tabular}

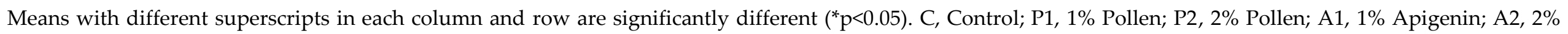
Apigenin 
Table 2. Effect of bee pollen and apigenin extracts on sensory parameters in beef meatballs.

\begin{tabular}{|c|c|c|c|c|c|c|c|c|c|c|c|c|}
\hline Sensory attributes & $\begin{array}{l}\text { Storage } \\
\text { Period }\end{array}$ & $\mathrm{C}$ & SD & P1 & SD & P2 & SD & A1 & SD & A2 & SD & Mean* \\
\hline \multirow{5}{*}{ Color } & 1 & 5.00 & 0.00 & 5.00 & 0.00 & 5.00 & 0.00 & 5.00 & 0.00 & 5.00 & 0.00 & 5.00 \\
\hline & 3 & 4.83 & 0.41 & 4.83 & 0.41 & 4.50 & 0.55 & 4.83 & 0.41 & 4.50 & 0.55 & 4.70 \\
\hline & 7 & 4.67 & 0.52 & 4.67 & 0.52 & 4.33 & 0.52 & 4.67 & 0.52 & 4.17 & 0.41 & 4.50 \\
\hline & 14 & 4.50 & 0.55 & 4.33 & 0.52 & 4.17 & 0.41 & 4.33 & 0.52 & 4.00 & 0.00 & 4.27 \\
\hline & Mean & 4.75 & 0.32 & 4.71 & 0.29 & 4.50 & 0.32 & 4.71 & 0.29 & 4.42 & 0.20 & \\
\hline \multirow{5}{*}{ Flavor } & 1 & 5.00 & 0.00 & 5.00 & 0.00 & 5.00 & 0.00 & 4.83 & 0.41 & 4.83 & 0.41 & 4.93 \\
\hline & 3 & 4.83 & 0.41 & 5.00 & 0.00 & 4.83 & 0.41 & 4.67 & 0.52 & 4.50 & 0.55 & 4.77 \\
\hline & 7 & 4.50 & 0.55 & 4.67 & 0.52 & 4.83 & 0.41 & 4.33 & 0.52 & 4.17 & 0.41 & 4.50 \\
\hline & 14 & 4.00 & 0.63 & 4.17 & 0.41 & 4.33 & 0.52 & 3.83 & 0.75 & 3.67 & 0.52 & 4.00 \\
\hline & Mean & 4.58 & 0.20 & 4.71 & 0.10 & 4.75 & 0.00 & 4.42 & 0.26 & 4.29 & 0.25 & \\
\hline \multirow{5}{*}{ Tenderness } & 1 & 5.00 & 0.00 & 5.00 & 0.00 & 5.00 & 0.00 & 5.00 & 0.00 & 5.00 & 0.00 & 5.00 \\
\hline & 3 & 4.67 & 0.52 & 4.67 & 0.52 & 4.67 & 0.52 & 4.50 & 0.55 & 4.50 & 0.55 & 4.60 \\
\hline & 7 & 4.33 & 0.52 & 4.50 & 0.55 & 4.67 & 0.52 & 4.33 & 0.52 & 4.17 & 0.41 & 4.40 \\
\hline & 14 & 4.00 & 0.00 & 4.00 & 0.00 & 4.50 & 0.55 & 3.83 & 0.41 & 3.83 & 0.41 & 4.03 \\
\hline & Mean & 4.50 & 0.00 & 4.54 & 0.10 & 4.71 & 0.25 & 4.42 & 0.26 & 4.38 & 0.21 & \\
\hline \multirow{5}{*}{ Juiciness } & 1 & 5.00 & 0.00 & 5.00 & 0.00 & 5.00 & 0.00 & 5.00 & 0.00 & 5.00 & 0.00 & 5.00 \\
\hline & 3 & 4.83 & 0.41 & 4.83 & 0.41 & 5.00 & 0.00 & 4.67 & 0.52 & 5.00 & 0.00 & 4.87 \\
\hline & 7 & 4.33 & 0.52 & 4.67 & 0.52 & 4.83 & 0.41 & 4.50 & 0.55 & 4.83 & 0.41 & 4.63 \\
\hline & 14 & 3.67 & 0.52 & 3.83 & 0.41 & 4.00 & 0.00 & 3.67 & 0.52 & 4.00 & 0.00 & 3.83 \\
\hline & Mean & 4.46 & 0.25 & 4.58 & 0.20 & 4.71 & 0.10 & 4.46 & 0.29 & 4.71 & 0.10 & \\
\hline \multirow{5}{*}{$\begin{array}{l}\text { Overall } \\
\text { acceptability }\end{array}$} & 1 & 5.00 & 0.00 & 5.00 & 0.00 & 5.00 & 0.00 & 5.00 & 0.00 & 5.00 & 0.00 & 5.00 \\
\hline & 3 & 5.00 & 0.00 & 5.00 & 0.00 & 5.00 & 0.00 & 4.83 & 0.41 & 4.83 & 0.41 & 4.93 \\
\hline & 7 & 4.50 & 0.55 & 4.50 & 0.55 & 4.50 & 0.55 & 4.50 & 0.55 & 4.50 & 0.55 & 4.50 \\
\hline & 14 & 4.33 & 0.52 & 4.33 & 0.52 & 4.33 & 0.52 & 4.33 & 0.52 & 4.00 & 0.63 & 4.27 \\
\hline & Mean & 4.71 & 0.19 & 4.71 & 0.19 & 4.71 & 0.19 & 4.67 & 0.20 & 4.58 & 0.30 & \\
\hline
\end{tabular}

Sensory scores were 5 for excellent, 4 for very good, 3 for good, 2 for fair, and 1 for poor. Mean in each row having different superscript varies significantly at values ${ }^{*} \mathrm{p}<0.05$. 
Table 3. Phenolics composition of bee pollen extracts.

\begin{tabular}{lc}
\hline Compounds & Bee pollen $(\mathbf{m g} / \mathbf{m L}$ extract) \\
\hline Gallic acid & $5.17 \pm 0.04$ \\
Vanilic acid & $0.81 \pm 0.01$ \\
p- Coumaric acid & $1.9 \pm 0.11$ \\
Ferulic acid & $4.73 \pm 0.08$ \\
Rutin & $2.83 \pm 0.13$ \\
Myricetin & $1.88 \pm 0.15$ \\
Quercetin & $5.42 \pm 0.10$ \\
Kaempferol & $4.94 \pm 0.03$ \\
Apigenin & $8.16 \pm 0.04$ \\
Naringenin & $3.58 \pm 0.08$ \\
Luteolin & $2.24 \pm 0.07$ \\
\hline
\end{tabular}

Mean values \pm standard deviation of triplicate determinations are reported.

The range of overall recorded color-score was 4.75 to 4.29 , tenderness score was 4.71 to 4.38 , juiciness score was 4.71 to 4.46 and overall acceptability score was 4.71 to 4.58 (Table 2). The range of different day's intervals of overall observation of overall acceptability score 4.27 to 5.00. Among five treatments most preferable color and juiciness was observed from 1\% (P1) tenderness and overall acceptability were observed from $2 \%$ (P2) and the flavor was observed from $2 \%$ (P2) bee pollen extract. With increasing of sensory scores were also reported some researches (Huang et al., 2005; Turhan et al., 2014).

Apigenin, quercetin, gallic acid, ferulic acid, kaempferol, naringenin, rutin and luteolin were recognized as the main phenolic components in bee pollen extract as shown in Table 3. Some components such as myricetin, p-coumaric acid and vanilic acid were also found in traces. All these components are known as phenolic composition of bee pollen samples (Mohdaly et al., 2015). Some other studies were developed concerning the phenolic composition of bee pollen extract (Almeida et al., 2017), apigenin $(8.16 \mathrm{mg} / \mathrm{mL})$ was the flavonoid most abundant in the bee pollen extract, followed by quercetin $(5.12 \mathrm{mg} / \mathrm{mL})$. Almeida et al. (2017) identified seven phenolic compounds in the bee pollen from lyophilized extracts. Among the identified constituents, several compounds with known antioxidant, antimicrobial, anticancer and anti-inflammatory such as flavonoids and phenolic acids, were present (Demir et al., 2020).

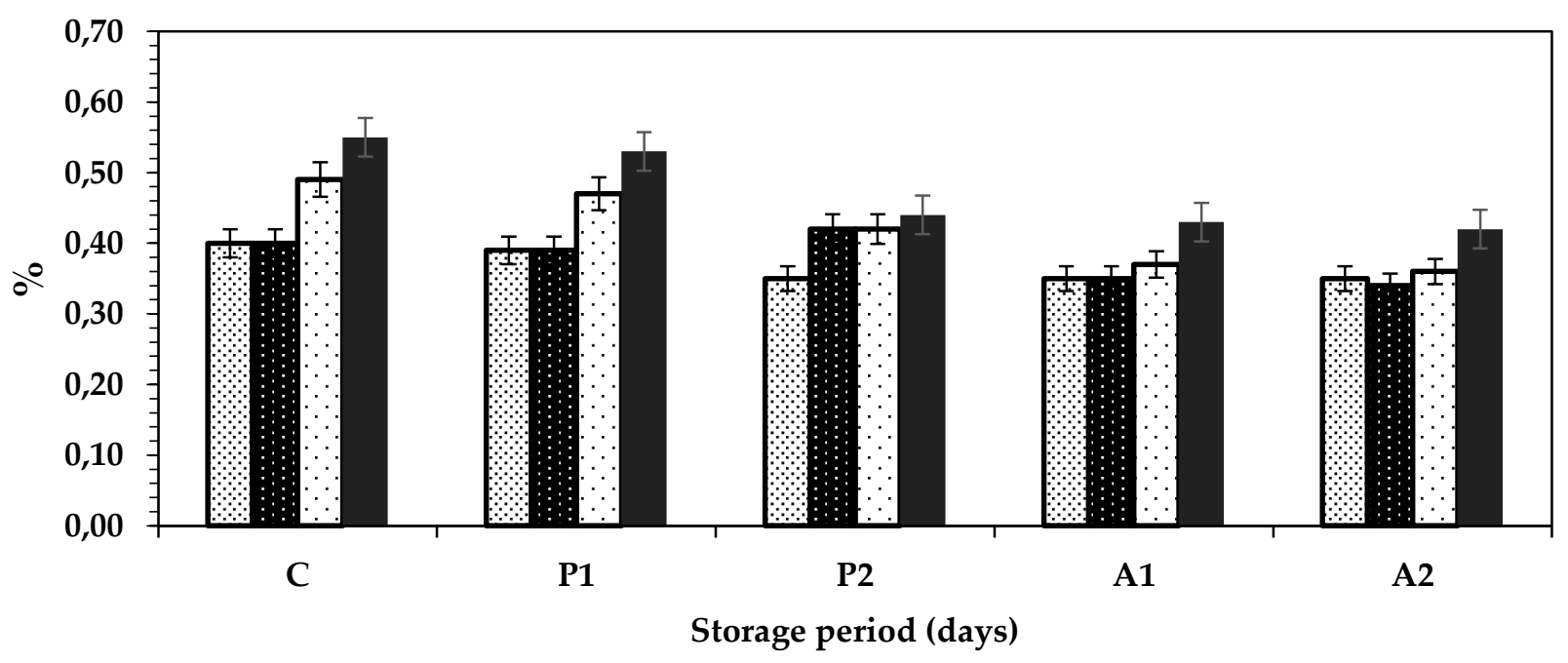

@Day 1 Day 3 口Day 7 Day 14

Figure 1. Effects of bee pollen and apigenin on free fatty acids value of meatballs at different storage durations. 


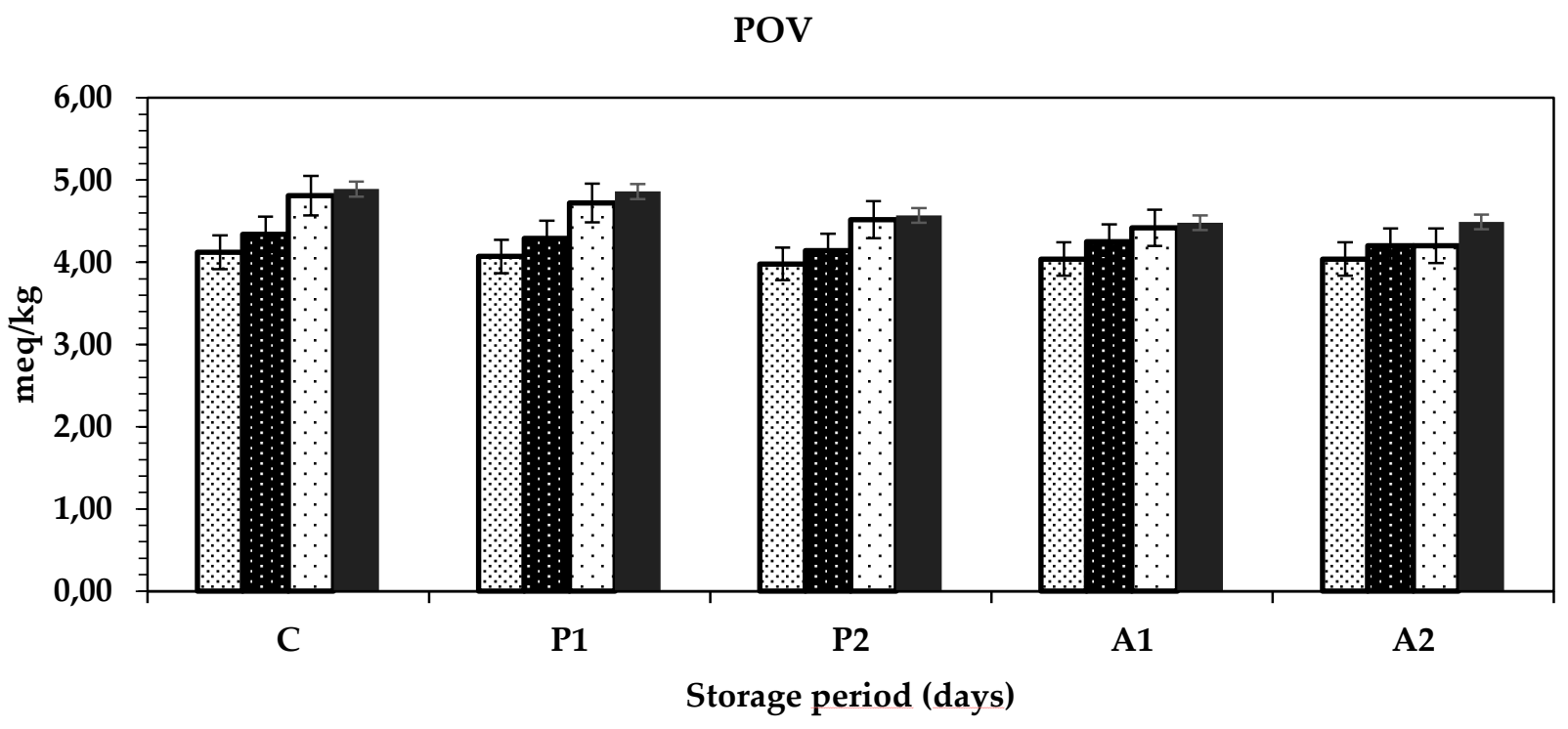

๑Day 1 Day 3 QDay 7 Day 14

Figure 2. Changes in POV and meatballs during storage.

TBARS

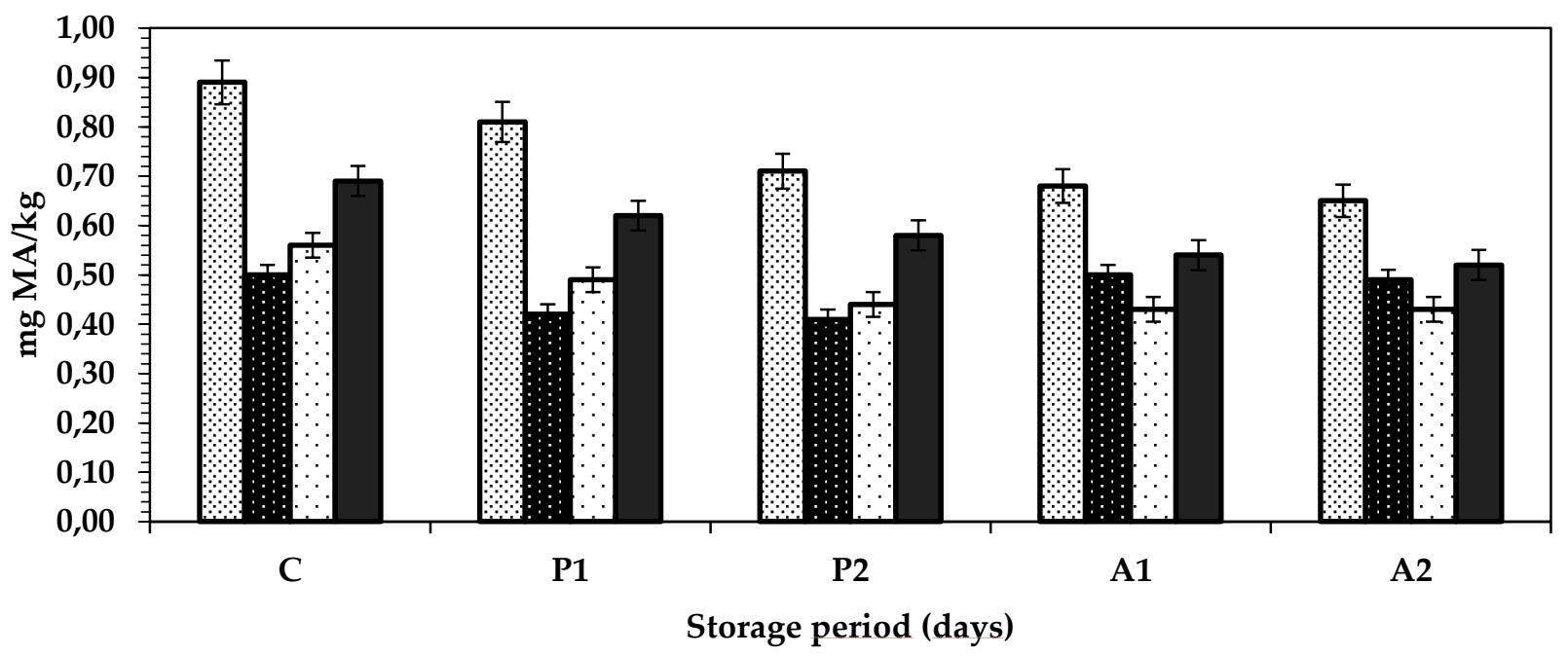

DDay 1 DDay 3 DDay 7 Day 14

Figure 3. Changes in TBARS of meatballs during storage.

The most preferable FFA value was observed on the $1^{\text {st }}$ day and less preferable FFA value was observed on the $14^{\text {th }}$ day. The most preferable value was observed from $2 \%$ apigenin (A2) extract and then observed 1\% A2, 2\% P2 and 1\% P1 (Figure 1). The FFA value (0.46) in the control group was remarkably $(p<0.05)$ higher than the values of the samples added with bee pollen extracts $(\mathrm{P} 1>\mathrm{P} 2)$. In a study found that sausages showed an increasing FFA content over time (Siddiqua et al., 2018).

Throughout the storage period, POV was generally higher in the control group compared to treatment groups (Figure 2). The most preferable POV was observed at $2 \%$ bee pollen (P2)/apigenin (A2) extracts. The lowest amount of POV indicates that this product is most preferable for consumer's 
health. Siddiqua et al. (2018) obtained similar results in beef meatball with tulsi (Ocimum sanctum) leaves extract.

TBARS value is one of the most completely used experiments for measuring the lipid oxidation of meat and meat products. TBARS values of meatball samples were affected by bee pollen and apigenin added (except 0 days of storage) and storage process $(p<0.05)$. While on the 7 th day of the storage process, the maximum TBARS values were defined in control and meatballs prepared with $1 \%$ and $2 \%$ bee pollen, the minimum values were defined in meatballs prepared with $1 \%$ and $2 \%$ apigenin extracts $(p<0.05)$. A similar situation was also observed on the 14th day of the storage. TBARS values of the samples achieved max grades of 0.89 , $0.81,0.71,0.68$ and $0.65 \mathrm{mgMA} / \mathrm{kg}$ for control and meatballs formulated with $1 \%$, $2 \%$ bee pollen/apigenin, respectively (Figure 3). Mincing, mixing ferric hematin pigments and sodium chloride were accountable for this rise. Mincing and mixture break muscle structure and enhancement the surface picked out to oxygen and another oxidation catalysis. Ferric hematin pigments simplify the transference of electrons significant to raised ratios of free radical creation and thus supports the lipid oxidation (Turhan et al., 2017; Rubio et al., 2018). Natural antioxidants, particularly polyphenols, are the major plant compounds which have the capability to decreased the oxidative damage of a tissue implicitly by increasing natural defenses of cell and/or straight by depurating the free radical species struggle pathological irregularities created by physicochemical reactive oxygen species (Du et al., 2010). Jung et al. (2010) recorded that natural antioxidant agents have considerable administration prospective for consumer's acceptability, stability and during storage of meat products.

\section{CONCLUSION}

From the study it may be concluded that $2 \%$ of bee pollen extract as natural antioxidant may be used beef meatball preparation. On the basis of sensory evaluation, physicochemical properties, biochemical analysis and microbial assessment indicated that $2 \%$ bee pollen extract showed better results in the preparation of beef meatball compare to control and other treatments. The results of this study indicated that bee pollen addition had a significant effect on the color changes, lipid oxidation and microbial quality of meatballs during frozen storage. The addition of pollen retarded lipid oxidation and inhibited microbial growth. Thus, bee pollen can be successfully used as a natural antioxidant and antimicrobial in meatballs.

\section{ACKNOWLEDGMENTS}

Conflict of Interests: The authors declared that there is no conflict of interests.

Financial Disclosure: The authors declared that this study has received no financial support.

Author's Contributions: All authors (TD and SA) contributed to the study conception and design. Supervision/Consultancy (SA and TD), Data collecting (TD), Literature research (SA and TD), Writing the article (TD and SA), Critical review (TD and SA). All authors read and approved the final manuscript (TD: Tuğba Demir; SA: Sema Ağaoğlu).

\section{REFERENCES}

Ahn J, Grün IU, Mustapha A. Antimicrobial and antioxidant activities of natural extracts in vitro and in ground beef. J Food Protect. 2004; 67(1):148-155.

Chen JH, Ren Y, Seow J, Liu T, Bang WS, Yuk HG. Intervention technologies for ensuring microbiological safety of meat: current and future trends. Compr Rev Food Sci F. 2012; 11(2):119-132.

Burkepile DE, Parker JD, Woodson CB, et al. Chemically mediated competition between microbes and animals: microbes as consumers in food webs. Ecology. 2006; 87:28212831.

de Florio Almeida J, dos Reis AS, Heldt LFS, et al. Lyophilized bee pollen extract: A natural antioxidant source to prevent lipid oxidation in refrigerated sausages. Lwt-Food Sci Technol. 2017; 76:299-305.

Demir T, Akpınar Ö, Kara H, Güngör H. Cherry stem phenolic compounds: optimization of extraction conditions and in vitro evaluations of antioxidant, antimicrobial, antidiabetic, anti-inflammatory, and cytotoxic activities. J Food Proces Preserv. 2020; 44(10):e14804.

Demir T, Ağaoğlu S. Antimicrobial and antioxidant activity of different herbal tea combinations. TJVR. 2020; 4(2):69-77.

Demir T. Effects of green tea powder, pomegranate peel powder, epicatechin and punicalagin additives on antimicrobial, antioxidant potential and quality properties of raw meatballs. Molecules. 2021; 26(13): 4052.

Doulgeraki AI, Ercolini D, Villani F, Nychas GJE. Spoilage microbiota associated to the storage of raw meat in different conditions. Int. J Food Microbiol. 2012; 157(2):130-141.

Du J, Zeng Y, Wang H, et al. CuZnSOD gene expression and its relationship with anti-oxidative capacity and pork quality. South African J Anim Sci. 2010; 40(3):265-272.

Fernandez-Lopez J, Zhi N, Aleson-Carbonell L, Pérez-Alvarez JA, Kuri V. Antioxidant and antibacterial activities of natural extracts: application in beef meatballs. Meat Sci. 2005; 69(3):371-380. 
Freire KR, Lins A, Dórea MC, Santos FA, Camara, CA, Silva T. Palynological origin, phenolic content, and antioxidant properties of honeybee-collected pollen from Bahia, Brazil. Molecules. 2012; 17(2):1652-1664.

Graikou K, Kapeta S, Aligiannis N, et al. Chemical analysis of Greek pollen-Antioxidant, antimicrobial and proteasome activation properties. Chem Cent J. 2011; 5(1):1-9.

Hintz T, Matthews KK, Di R. The use of plant antimicrobial compounds for food preservation. BioMed Res Int. 2015; 2015:1-12.

Huang SC, Shiau CY, Liu TE, Chu CL, Hwang DF. Effects of rice bran on sensory and physico-chemical properties of emulsified pork meatballs. Meat Science. 2005; 70(4):613-619.

Human, H, Nicolson SW. Nutritional content of fresh, beecollected and stored pollen of Aloe greatheadii var. davyana (Asphodelaceae). Phytochemistry. 2006; 67(14):1486-1492.

Jiao Y, Quek SY, Gu M, Guo Y, Liu Y. Polyphenols from thinned young kiwifruit as natural antioxidant: Protective effects on beef oxidation, physicochemical and sensory properties during storage. Food Contro. 2020; 108:106870.

Jung S, Choe JH, Kim B, Yun H, Kruk ZA, Jo C. Effect of dietary mixture of gallic acid and linoleic acid on antioxidative potential and quality of breast meat from broilers. Meat Sci. 2010; 86(2):520-526.

Manessis G, Kalogianni AI, Lazou T, Moschovas M, Bossis I, Gelasakis AI. Plant-derived natural antioxidants in meat and meat products. Antioxidants. 2020; 9(12):1215.

Mohdaly AA, Mahmoud AA, Roby MH, Smetanska I, Ramadan MF. Phenolic extract from propolis and bee pollen: composition, antioxidant and antibacterial activities. J Food Biochem. 2015; 39(5):538-547.

Morais M, Moreira L, Feás X, Estevinho LM. Honeybeecollected pollen from five Portuguese Natural Parks: Palynological origin, phenolic content, antioxidant properties and antimicrobial activity. Food Chem Toxicol. 2011; 49(5):1096-1101.

Rubio B, Martínez B, Sánchez MJ, García-Cachán MD, Rovira J, Jaime I. Study of the shelf life of a dry fermented sausage "salchichon" made from raw material enriched in monounsaturated and polyunsaturated fatty acids and stored under modified atmospheres. Meat Sci. 2007; 76(1):128-137.

Rukunudin IH, White PJ, Bern CJ, Bailey TB. A modified method for determining free fatty acids from small soybean oil sample sizes. JAOCS. 1998;7 5(5):563-568.
Rzepecka-Stojko A, Pilawa B, Ramos P, Stojko J. Antioxidative properties of bee pollen extracts examined by EPR spectroscopy. Apicultural Sci. 2012; 56(1):23.

Shahbazi Y, Karami N, Shavisi N. Effect of Ziziphora clinopodioides essential oil on shelf life and fate of Listeria monocytogenes and Staphylococcus aureus in refrigerated chicken meatballs. J Food Saf. 2018; 38(1):e12394.

Sharma P, Jha AB, Dubey RS, Pessarakli M. Reactive oxygen species, oxidative damage, and antioxidative defense mechanism in plants under stressful conditions. J Bot. 2012;217037:1-26

Siddiqua T, Hossain MA, Khan M, Hashem MA. Formulation of value added beef meatball using tulsi (Ocimum sanctum) leaf extract as a source of natural antioxidant. J Bangladesh Agril Univ. 2018; 16(2):260-265.

Turgut SS, Soyer A, Işıkçı F. Effect of pomegranate peel extract on lipid and protein oxidation in beef meatballs during refrigerated storage. Meat Sci. 2016; 116:126-132.

Turhan S, Saricaoglu FT, Mortas M, Yazici F, Genccelep H. Evaluation of color, lipid oxidation and microbial quality in meatballs formulated with bee pollen during frozen storage. J Food Proces Preserv. 2017; 41(3):e12916.

Turhan S, Yazici F, Saricaoglu FT, Mortas M, Genccelep H. Evaluation of the nutritional and storage quality of meatballs formulated with bee pollen. Korean J Food Sci Anim Res., 2014; 34(4):423.

Turkish Standards Institution (TSE). TS EN ISO 4833-2 Microbiology of the food chain - Horizontal method for the enumeration of microorganisms - Part 2: Colony count at 30 degrees $C$ by the surface plating technique, 2014.

Turkish Standards Institution (TSE). TS ISO 4832 Microbiology of food and animal feeding stuffs - Horizontal method for the enumeration of coliforms - Colony-count technique, 2010.

Turkish Standards Institution (TSE). TS ISO 21527-1:2008 Microbiology of food and animal feeding stuffs -- Horizontal method for the enumeration of yeasts and moods-Part 1 : Colony count technique in products with water activity greater than 0.95, 2012.

Volpe MG, Siano F, Paolucci M, et al. Active edible coating effectiveness in shelf-life enhancement of trout (Oncorhynchusmykiss) fillets. LWT-Food Sci Technol. 2015; 60(1):615-622.

Zhang W, Xiao S, Samaraweera H, Lee EJ, Ahn DU. Improving functional value of meat products. Meat Sci. 2010; 86(1):1531. 